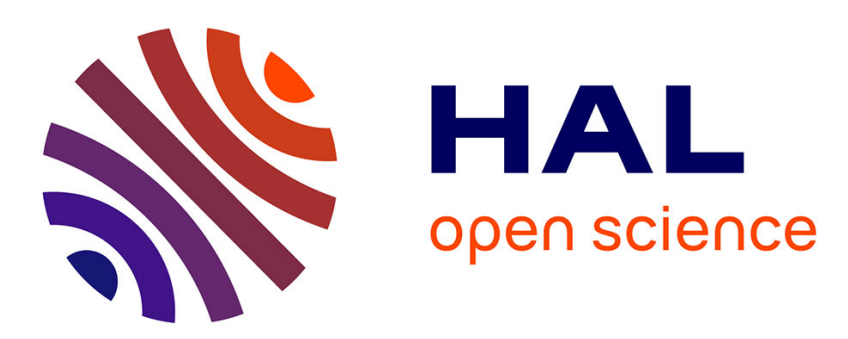

\title{
SLOW PARAMAGNETIC RELAXATION OF SOME PSEUDO-TETRAHEDRAL FERROUS COMPOUNDS IN ZERO FIELD
}

W. Reiff, C. Nicolini, B. Dockum

\section{- To cite this version:}

W. Reiff, C. Nicolini, B. Dockum. SLOW PARAMAGNETIC RELAXATION OF SOME PSEUDOTETRAHEDRAL FERROUS COMPOUNDS IN ZERO FIELD. Journal de Physique Colloques, 1979, 40 (C2), pp.C2-230-C2-232. 10.1051/jphyscol:1979282 • jpa-00218680

\section{HAL Id: jpa-00218680 https://hal.science/jpa-00218680}

Submitted on 1 Jan 1979

HAL is a multi-disciplinary open access archive for the deposit and dissemination of scientific research documents, whether they are published or not. The documents may come from teaching and research institutions in France or abroad, or from public or private research centers.
L'archive ouverte pluridisciplinaire HAL, est destinée au dépôt et à la diffusion de documents scientifiques de niveau recherche, publiés ou non, émanant des établissements d'enseignement et de recherche français ou étrangers, des laboratoires publics ou privés. 


\title{
SLOW PARAMAGNETIC RELAXATION OF SOME PSEUDO-TETRAHEDRAL FERROUS COMPOUNDS IN ZERO FIELD ${ }^{+}$
}

\author{
W.M. Reiff ${ }^{+}$C. Nicolini and B. Dockum \\ Department of Chemistry, Hortheastern University, Boston, Mass. 02115, U.S.A.
}

\begin{abstract}
Résumé.- La relaxation paramagnétique lente en 1'absence de champ magnétique extérieur a êté observée dans des composés tétraédriques de fer (II) pour la première fois. Les spectres Mössbauer de $\mathrm{Fe}(2,9$ di- $\mathrm{CH}_{3}$-phenanthroline) (NCS) $)_{2}$ et $\mathrm{Fe}\left(2,9 \mathrm{di}-\mathrm{CH}_{3}-4,7\right.$ di $\phi$-phenanthroline) (NCS) 2 montrent une structure hyperfine magnétique dans le domaine de $20 \mathrm{~K}$ à 1,6 K. Au contraire, les complexes correspondants de chlorure montrent un taux de relaxation rapide à toutes températures en l'absence de champ magnétique. Des résultats de mesures de susceptibilitê magnétique à basse température et de spectroscopie Mössbauer indiquent que $\mathrm{D}$ change de signe (de positif en négatif) lorsqu'on passe de $\mathrm{CI}^{-}$à NCS- respectivement. Les spectres Mössbauer jusqu'à $1.6 \mathrm{~K}$ confirment la relaxation paramagnêtique rapide pour les autres composés analogues pseudo-tétraédriques (par exemple, Fe(biquinoline) $\mathrm{X}_{2}, \mathrm{X}=\mathrm{Cl}^{-}$, $\left.\mathrm{NCS}^{-}\right)$. La relaxation lente est particulière au systême 2,9 -diCH ${ }_{3}$-phenanthroline.
\end{abstract}

Abstract. Slow (zero field)paramagnetic relaxation is reported for undiluted tetrahedral ferrous monomers for the first time. The Mössbauer spectra of $\mathrm{Fe}\left(2,9\right.$ di- $\mathrm{CH}_{3}$-phenanthroline) (NCS) 2 and $\mathrm{Fe}(2,9$ di- $\mathrm{CH}_{3} 4,7 \mathrm{di}-\phi$-phenanthroline) (NCS) 2 exhibit magnetic hyperfine splitting in the range $20 \mathrm{~K} \mathrm{to} 1.6 \mathrm{~K}$ while the corresponding chlorides are rapidly relaxing paramagnets at all temperatures in zero field. Low temperature susceptibility and Mössbauer results indicate that $\mathrm{D}$ changes sign from positive to negative from the $\mathrm{Cl}^{-}$to $\mathrm{NCS}^{-}$respectively with the foregoing ligands. Mössbauer spectra to $1.6 \mathrm{~K}$ confirm rapid paramagnetic relaxation for other pseudo-tetrahedral analogues (e.g. Fe(biquinoline) $X_{2}$, $\left.\mathrm{X}=\mathrm{Cl}, \mathrm{NCS}^{-}\right)$. The slow relaxation is then peculiar to the $2,9 \mathrm{di}-\mathrm{CH}_{3}$-phenanthroline system.

1. Introduction and Experimental.- While still relatively rare for high-spin ferrous, slow paramagnetic relaxation has recently been demonstrated for isix coordinate iron (II) compounds /1,2/. To our knowledge this phenomenon has not been previously documented for simple tetrahedral systems and in this work we report what is apparently the first observation of slow zero field paramagnetic relaxation and resolved magnetic hyperfine splitting in the Mössbauer spectra of distorted, monomeric, pseudo-tetrahedral coordination compounds of iron(II) with simple organo ligands. The compounds involved belong to the family $\left[\mathrm{Fe}\left(2,9 \mathrm{di}-\mathrm{CH}_{3}-\right.\right.$ phenanthroline $\left.) \mathrm{X}_{2}\right], \mathrm{X}=\mathrm{Cl}^{-}$, $\mathrm{Br}^{-}, \mathrm{I}_{1}^{-}$and $\mathrm{NCS}^{-}$. Hereafter, the ligand 2,9-di$\mathrm{CH}_{3}$-phenanthroline is abbreviated as dmp. We have studied the slow relaxation in this system of compounds using Mössbauer spectroscopy and Faraday susceptibility apparatus previously described $13,4 /$ for undiluted powder samples. The compounds are pseudotetrahedral monomers as shown by near infrared visible and far infrared spectra /5/ and isomer shifts $/ 6 /$ as well as solution conductivity measurements /7/ (soluble non-electrolyte behavior) in accord with stoichiometries indicated by chemical analyses. In addition, $X-r a y$ powder studies /8/ show that $\mathrm{Fe}(\mathrm{dmp}) \mathrm{Cl}_{2}$ is isomorphous to $\mathrm{Zn}(\mathrm{dmp}) \mathrm{Cl}_{2}$ for

This research was supported by the NSF Division of Materials Research, Grant No. DMR-77-12625. which a single crystal $\mathrm{X}$-ray investigation $/ 9 /$ of its structure clearly indicates monomeric pseudotetrahedral structure units.

2. Mössbauer Spectroscopy Results.- The Mössbauer spectrum of the $\mathrm{Cl}^{-}$system over the range 1.6 to $300 \mathrm{~K}$ gives no evidence of magnetic hyperfine splitting implying positive zero field splitting $(D \geq 0)$ while the corresponding $\mathrm{NCS}^{-}$system exhibits progressively resolved splitting in the decreasing temperature range 20 to $1.6 \mathrm{~K}$, implying $\mathrm{D}<0$. It is $1 \mathrm{i}$ kewise found that $D$ goes from positive to negative ongoing from $\mathrm{Fe}\left(2,9 \mathrm{di}-\mathrm{CH}_{3}-4,7-\mathrm{di}\right.$-pheny1-phenanthroline) $\mathrm{Cl}_{2}$ to corresponding $\mathrm{NCS}^{-}$where in the latter hyperfine splitting occurs in the rarge 4.2 to $1.6 \mathrm{~K}$ suggesting a smaller $|D|$ for the phenylated system. Some typical Mössbauer spectra for the extremes of slow and rapid relaxation are shown in figure 1 for the case of $\mathrm{Fe}(\mathrm{dmp})$ (NCS) ${ }_{2}$ where the transitions of the quadrupole doublet of the rapidly relaxing phase have completely disappeared at low temperatures. A small applied field ( $23 \mathrm{kG}$ ) at $4.2 \mathrm{~K}$ results in a Mössbauer spectrum quite similar to that observed in zero field at $3 \mathrm{~K}$, suggesting field induced slow relaxation at higher temperatures. A more complete study of the field dependence of the Mössbauer spectra of these compounds over the range $1.6 \mathrm{~K}$ to $300 \mathrm{~K}$ and $O$ to $100 \mathrm{kG}$ is the subject of future publication and is now in progress. To conclude this section we point out that there is no evidence of the foregoing 
relaxation broadening in the Mössbauer spectra of other tetrahedral analogues : e.g. Fe(biquinoline) $\mathrm{x}_{2}$ (for $\left.\mathrm{H}_{0}=0\right)\left(\mathrm{X}=\mathrm{CI}^{-}, \mathrm{NCS}^{-}\right)$behave as rapidly relaxing paramagnets to as $10 \mathrm{~W}$ as $1.6 \mathrm{~K}$. Thus the observed slow relaxation appears to be peculiar to the anion ligation of the 2,9 di-CH $3-$ phenanthroline systems.

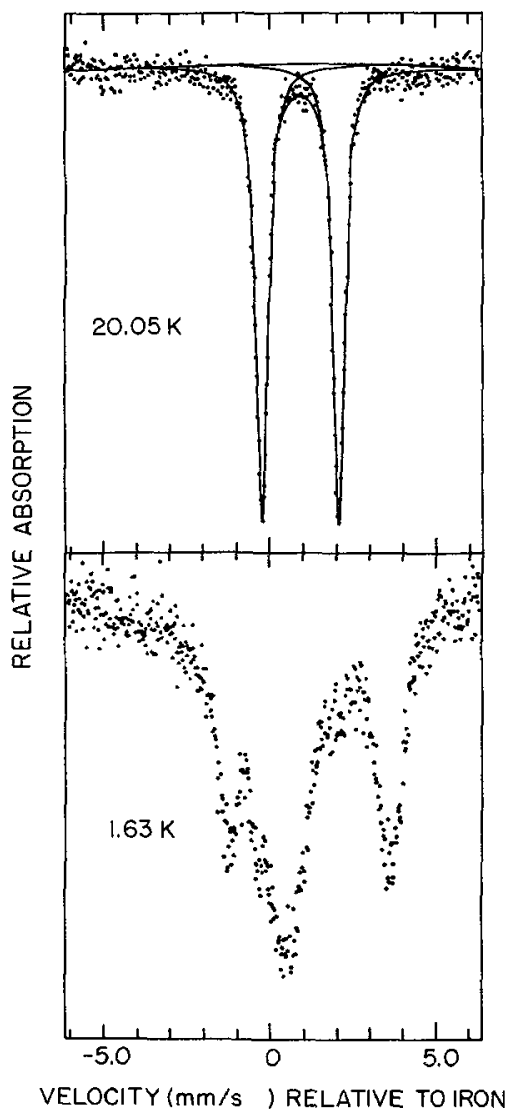

Fig. 1 : Mossbauer spectrum of $\mathrm{Fe}(\mathrm{dmp})(\mathrm{NCS})_{2}$ at $20.05 \mathrm{~K}$.

Fig. 2 : Mössbauer spectrum of $\mathrm{Fe}(\mathrm{dmp})(\mathrm{NCS})_{2}$ at $1.63 \mathrm{~K}$.

3. Susceptibility Studies, - The foregoing Mössbauer results, i.e $D<0$ for $F e$ (dmp) (NCS) 2 and $D>0$ for the chloride are further supported in the temperature dependence of the effective moment (Figure 3 ). The figure 3 shows $\mu_{\text {eff }}$ versus $T$ for an applied field of $1.6 \mathrm{kG}$ for the thiocyanate in powder form. The complex, however, apparently behaves as an oriented single crystal sample in our Faraday balance sample bucket owing to large magnetic anisotropy and significant sample polarization and alignment in the field. The temperature dependence of the molar susceptibility is unremarkable. However, the novel low temperature maximum and large value of $\mu$ are expected $/ 10,11 /$ for a single crysta 1 with $\mu_{1}>\mu_{\perp}$ implying $\mathrm{D}<0$ and large $\left(\mathrm{\sim}-2\right.$ to $\left.-5 \mathrm{~cm}^{-1}\right)$. In the present NCS $^{-}$compound $\mu$ has a value of $5.60 \mu \beta$ at $104 \mathrm{~K}$, rises to a maximum of $8.10 \mu \beta$ at $3.01 \mathrm{~K}$ and then, decreases to $6.94 \mu \beta$ at $1.5 \mathrm{~K}$. In the case of $D>0$ and for comparable $|D|$, one expects $\mu_{\perp}>\mu_{11}$ and $\left|\mu_{\perp}-\mu_{11}\right|$ i.e the anisotropy to be smaller with the maximum value of $\mu$ smaller as well. A powder sample of the latter type would then, be expected to show a less pronounced low temperature maximum in $\mu$ if at all.

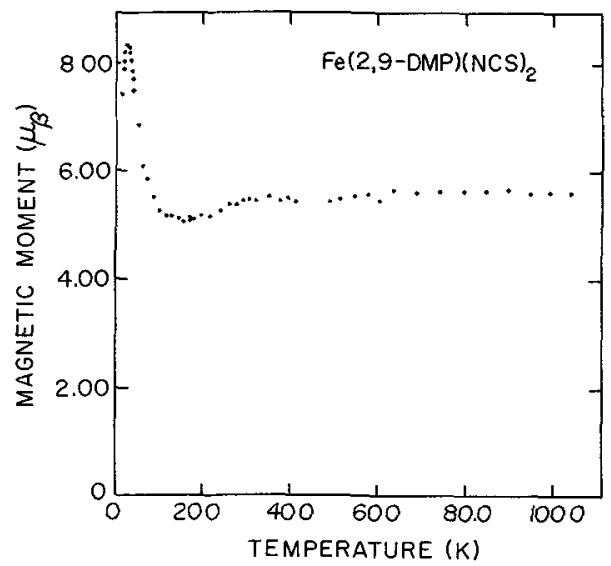

Fig. 3 : Temperature dependence of the magnetic moment $(\mu)$ for $\mathrm{Fe}(\mathrm{dmp})(\mathrm{NCS})_{2}$.

Our study of $\mu$ versus $T$ for a powder sample of $\mathrm{Fe}(\mathrm{dmp}) \mathrm{Cl}_{2}$ over the range $300 \mathrm{~K}$ to $1.6 \mathrm{~K}$ shows essentially "normal" powder behavior, i.e. no pronounced maximum in $\mu$ suggesting $D$ positive in accord with the low temperature Mössbauer spectra. For the latter compound $\mu$ decreases from $5.07 \mu_{\beta}$ at $302.78 \mathrm{~K}$ to $2.66 \mu_{\beta}$ at $1.57 \mathrm{~K}$, a variation consistent $/ 12 /$ $\mathrm{D} \sim+5 \mathrm{~cm}^{-1}$. The $\mathrm{D}$ values refer to zero field splitting of the ground spin quintet of high spin ferrous such that for $D<0$, the ground state is the Kramers doublet, $m_{s}= \pm 2$, with $m_{s}= \pm 1$ at $3|D|$ and $m_{s}=0$ at $4|\mathrm{D}|$ or alternatively for $\mathrm{D}>0, \mathrm{~m}_{\mathrm{s}}=0$ is the ground state with $m_{s}= \pm 1$ at $D$ and $m_{s}= \pm 2$ at $4 \mathrm{D}$. In summary, the magnetic susceptibility studies show $\mathrm{Fe}$ (dmp) (NCS) 2 and $\mathrm{Fe}$ (dmp) $\mathrm{Cl}_{2}$ to be Curie-Weiss paramagnets to low temperatures and that the hyperfine splitting of the latter is not due to an ordering process.

4. High Field Mössbauer Spectra.- Magnetically perturbed Mössbauer spectra have been determined for $\mathrm{Fe}$ (dmp) $\mathrm{Cl}_{2}$ for fields up to $25 \mathrm{kG}$ at $300 \mathrm{~K}$ at which temperature it is a rapidly relaxing paramagnet. The spectra indicate that $\eta^{\sim} \mathrm{O}$ and that quadrupole coupling constant is positive. Since $\mathrm{Q}\left({ }^{57} \mathrm{Fe}\right)$ is positive, $\mathrm{V}_{\mathrm{zz}}$ is positive. These results are consistent with an elongation along the two-fold axis of the tetrahedral $\mathrm{FeN}_{2} \mathrm{Cl}_{2}$ chromophore. This stabilizes the $\left|x^{2}-y^{2}\right\rangle$ orbital, or a linear combination of $\left|x^{2}-y^{2}\right\rangle$ and $\left|x^{2}-y^{2}\right\rangle$ weighted heavily with the 
former to give an orbital singlet $\left({ }^{5} \mathrm{~B}\right)$ ground term. The elongation of the $\mathrm{FeN}_{2} \mathrm{Cl}_{2}$ chromophore in $\mathrm{Fe}$ (dmp) $\mathrm{Cl}_{2}$ is a consequence of a small "bite" angle between the imine nitrogens of the bidentate ligand. From a single crystal study of the isomorphous $\mathrm{Zn}$ (dmp) $\mathrm{Cl}_{2}$, this "bite" angle ( $\mathrm{N}-\mathrm{Zn}-\mathrm{N}$ ) was measured to be $81^{\circ} / 9 /$. For complex with an undistorted tetrahedral geometry, the "bite" angle is $109^{\circ} 28^{\prime}$. It is expected that the other pseudotetrahedral complexes, $\mathrm{Fe}$ (biquinoline) $\mathrm{Cl}_{2}, \mathrm{Fe}$ (biquinoline)(NCS) 2 and $\mathrm{Fe}(\mathrm{dmp})(\mathrm{NCS})_{2}$ should also have a similar structure with a "bite" angle $(\mathrm{N}-\mathrm{Fe}-\mathrm{N})$ of the imine nitrogens of 2,2'-biquinoline and 2,9-dimethy1-1,10phenanthroline of $\sim 80^{\circ}$. The sign of $\mathrm{V}_{\mathrm{zz}}$ for each of the other pseudotetrahedral complexes should also be positive using reasoning analogous to the foregoing and this is, indeed, observed to be the case for their perturbed spectra.

5. Discussion.- It may not be totally unexpected that slow paramagnetic relaxation is readily observed ( $i . e$ in zero field above $1 \mathrm{~K}$ ) in pseudotetrahedral iron(II) compounds and perhaps more so than for octahedral systems. For an undistorted six coordinate iron(II) complex (in $o_{h}$ symetry), the ground state is ${ }^{5} \mathrm{~T}_{2 g}$, which contains residual orbital angular momentum. The system can then, rapidly relax through interactions between the electronic state and phonons of the lattice vibrations (spin lattice relaxation). Most "real" octahedral ferrous complexes are distorted such that the orbital ground state is a singlet $\left({ }^{5} \mathrm{~A}\right.$ or $\left.{ }^{5} \mathrm{~B}\right)$ which is further split via spin-orbit coupling to give a non-magnetic ground singlet and two excited Kramers doublets thus precluding slow relaxation. On the other hand, a compound with undistorted tetrahedral geometry $\left(\mathrm{T}_{\mathrm{d}}\right.$ symmetry) has a ${ }^{5} \mathrm{E}$ ground state. Any orbital angular momentum present in the ground state, is obtained by mixing the ${ }^{5} \mathrm{~T}_{2}$ excited state into the ground state via spin-orbit coupling. For the present systems this mixing effect should be small since the centroid of the excited ${ }^{5} \mathrm{~T}$ state is $w 6000$ to $7000 \mathrm{~cm}^{-1}$ above the ground ${ }^{5} \mathrm{E}$ state, and both of these states are split in complexes whose symetry is at most $C_{2 V}$. Our nearinfrared spectra indicate an excited $\left({ }^{5} \mathrm{~T}_{2}\right)$ state splitting of the order of 900 to $1000 \mathrm{~cm}^{-1}$ and a tetrahedral $1 \mathrm{OD}_{\mathrm{q}}$ of $6500 \mathrm{~cm}^{-1}$. The relatively temperature independent, quadrupole splitting $\Delta\left(\Delta \mathrm{E}_{\mathrm{Q}}\right)$ $w 0.3 \mathrm{~mm} / \mathrm{s}$ over the range 300 to $4.2 \mathrm{~K}$ ) and large magnitude ( 2.5 to $2.8 \mathrm{~mm} / \mathrm{s})$ for the present systems correspond to a ground ${ }^{5} \mathrm{E}$ state splitting at least $2500 \mathrm{~cm}^{-1}$ to $1000 \mathrm{~cm}^{-1}$. Since the free ion term spin- orbit coupling for the ferrous ion is $2100 \mathrm{~cm}^{-1}$, the preceding considerations indicate that spin-orbit coupling enhancement of the ground state orbital angular momentum will not be large. In the absence of residual orbital angular momentum such a tetrahedral complex can less readily interact with the lattice phonons and the spin-lattice relaxation times are expected to be longer as the temperature decreases. The remaining electronic relaxation process is then, spin-spin relaxation whose rate will be small for a ground $m_{s}= \pm 2$ corresponding to $D<0$, since highly forbidden $\Delta \mathrm{m}_{\mathrm{S}}= \pm 4$ transitions are involved. The exact nature of the high temperature relaxation process, i.e spin-spin vs.spin-lattice must await dilution studies. Thus we have initiated studies of the temperature dependence of ${ }^{57} \mathrm{Fe}$ diluted in the isomorphous diamagnetic $\mathrm{Zn}(\mathrm{dmp}) \mathrm{Cl}_{2}$ and $\mathrm{Zn}$ (dmp) (NCS) 2 hosts. However, previous experience with ferrous systems suggests that spin-lattice relaxation is the dominant relaxation mechanism.

\section{References}

1/ Nicolini, C., Chappert, J, and Mathieu, J.P., Inorg. Chem. 16 (1977) 3112 , and references therein.

12/ Price, D.C. Johnson, C.E. and Maartense, I., J. Phys. C : Solid State Phys. 10 (1977) 4843.

/3/ Reiff, W.M. and Cheng, C., Inorg. Chem. 16 (1977) 2097.

14/ Cheng, C., Wong, H. and Reiff, W.M., Inorg. Chem. 16 (1977) 819 .

15/ Reiff, W.M., Dockum, B., Weber, M.A. and Franke1, R.B., "Extended Interactions Between Metal Ions in Transition Metal Complexes", Ch. 15, 1974, p. 205.

16/ Reiff, W.M., Dockum, B., Torardi, C., Foner, S. and Franke1, R.B., "Extended Interactions Between Metal Ions in Transition Metal complexes", Ch.15 1974, p. 205.

/7/ Fox, D.B., Hall, J.R. and Plowman, R.A., Aust. J. Chem. 15 (1962) 235.

18/ Preston, H.S., Kennard, C.H.L., and Plowman, R.A. J. Inorg. Nuc1. Chem. 30 (1968) 1463.

19/ Preston, H.S., and Kennard, C.H.L., Chem. Commun. (1967) 708 .

ho/ Gregson, A.K. and Mitra, S., Chem. Phys. Lett. 3 (1969) 528.

AI/ Gerloch, M., Lewis, J. and S1ade, R.C., J. Chem. Soc. A (1969) 1422 .

A2/ Edwards, P.R., Johnson, C.E., and Williams, R.J.P., J. Chem. Phys. 47 (1967) 2074. 